Aksaray University
Journal of Science and Engineering
e-ISSN: 257-1277
http://dergipark.gov.tr/asujse
http://asujse.aksaray.edu.tr

Research Article

\title{
Stress Analysis of Different Metal Combinations Under Different Temperatures with Hybrid Joints
}

\author{
Emrullah Ozkan*, Kemal Aldas \\ Aksaray University, Engineering Faculty, Department of Mechanical Engineering, Aksaray, 68100, Turkey
}

-Received Date: 21 Mar 2017

-Accepted Date: 05 Apr 2017

-Published Online: 07 Apr 2017

\begin{abstract}
In this study, the stresses on various bonded joints which made from different sheet metals were investigated by using finite element method. The bonded joints planned as double-pin connection joints and adhesive bonded joints. Six different material combinations were used in joints. ANSYS finite element software was used for analysis, modelling and solution. The models were designed as 3D. The stresses which applied temperature load with tensile load to joints were investigated. As a result of studies, the compression stresses in the models got high values and reached the highest values at $\mathrm{X}$-axis direction. Furthermore, there were stress concentrations around the pin hole. Therefore, it can be easily seen that there may be bearing damage around stress zone.
\end{abstract}

\section{Keywords}

Pinned Joint, Adhesive Joint, Hybrid Joint, Stress Analysis

*Corresponding Author: Emrullah ÖZKAN, eozkan@aksaray.edu.tr 


Aksaray University
Journal of Science and Engineering
e-ISSN: 257-1277
http://dergipark.gov.tr/asujse
http://asujse.aksaray.edu.tr

Research Article

\title{
Karma Bağlantı Yapılmış Farkı Sıcaklıklar Altında Değişik Metal Kombinasyonların Gerilme Analizi
}

\author{
Emrullah Özkan*, Kemal Aldas \\ Aksaray Üniversitesi, Mühendislik Fakültesi, Makina Mühendisliği, Aksaray, 68100, Türkiye
}

\section{Özet}

$\mathrm{Bu}$ çalışmada, farklı metal plakalardan oluşan karma bağlantıda meydana gelen gerilmeler sonlu elemanlar yöntemi kullanılarak incelenmiştir. Karma bağlantı, seri çift pim bağlantısı ve yapıştırma bağlantısı kullanılarak oluşturulmuştur. Bağlantıda altı farklı malzeme kombinasyonu kullanılmıştır. Analiz, modelleme ve çözüm için ANSYS sonlu elemanlar yazılımı kullanılmıştır. Modelleme üç boyutlu olarak yapılmıştır. Karma bağlantıya çekme yükü ile birlikte sıcaklık yükü uygulanması sonucunda ortaya çıkan gerilmeler incelenmiştir. Yapılan çalışmalar sonucunda, modellerde basma gerilmelerinin yüksek değerlerde olduğu ve $\mathrm{x}$ ekseni yönünde en yüksek değerlere ulaştığı tespit edilmiştir. Ayrıca pim deliği çevrelerinde gerilme yığılmaları oluşmuştur. Dolayısıyla bağlantıda bu bölgelerde yatak hasarı olabileceği anlaşılmaktadır.

\section{Anahtar Kelimeler}

Pim Bağlantısı, Yapıştırma Bağlantısı, Karma Bağlantı, Gerilme Analizi

*Sorumlu Yazar: Emrullah ÖZKAN, eozkan@aksaray.edu.tr 


\section{GÍRİ̧̧}

Malzemelerin birleştirilmesinin geçmişten günümüze üzerinde uğraş verilen bir alan olduğu bilinmektedir. Teknolojinin ilerlemesiyle beraber bilinen mevcut birleştirme yöntemlerinden farklı olarak yeni birleştirme yöntemleri de sürekli üzerinde çalışılan bir konudur. Bu alanda, yapıştırıcı ile beraber farklı birleştirme yöntemlerinin kullanımının hızlı bir şekilde arttığı gözlenmektedir. Bu karma bağlantılar ile yüksek dayanıma sahip, korozyona karşı dirençli, sızdırmazlığı yüksek bağlantılar elde edilmektedir. Böylece tek başına kullanılan birleştirme bağlantılarında ortaya çıkabilecek olumsuzluklar önlenmeye çalışılmaktadır. Yapıştırıcı ve pim bağlantısının birlikte kullanılmasında, yapıştırıcı birleştirmesi ile gerilmenin tüm yüzeye yayılması sağlanmakta, pim bağlantısı ile delik çevrelerinde oluşan gerilme yığılmaları azaltılmak istenmektedir [1-2]. Yapıştırıcı ile birleştirilmiş veya pim bağlantısı kullanılmış bağlantıların analizinde sonlu elemanlar metodundan (FEM) faydalanılmaktadır.

Chan ve Vedhagiri [3] yapıştırıcı ve cıvata ile birleştirilmiş kompozit plakalardaki gerilmeleri incelemişlerdir. Sonlu elemanlar analizi sonuçları ile deneysel sonuçlar karşılaştırılmış, sonuçların birbiri arasında uyumlu olduğu gözlenmiştir. Apalak ve ark. [4] yapıştırılmış ve lazer nokta kaynağı kullanılmış çok katmanlı plakalarda sıcaklık dağılımı ve 1sıl gerilmeleri incelemişlerdir. Sıcaklık dağılımını geliştirdikleri Fortran programını kullanarak, ısıl gerilme analizlerini ise ANSYS sonlu elemanlar yazılımını kullanarak gerçekleştirmişlerdir. ElastikPlastik olarak gerçekleştirilen analizler sonucunda sıcaklık ve ısıl gerilme dağılımlarının kullanılan farklı malzemelere göre değişim gösterdiği tespit edilmiştir. Şen ve ark. [5] tarafından yapılan deneysel çalışmada, pim ve cıvata bağlantısı yapılmış bağlantılarda hasar analizi incelenmiştir. Çalışmada tek pim bağlantısı kullanılmış ve pim ile delik arasında boşluk bırakılarak, boşluğun hasar davranışını incelemek amacıyla testler yapıllmıştır. Şen ve Aldaş [6] yapıştırılmış ve pim bağlantısı uygulanmış alüminyum plakalarda farklı sıcaklıklar altındaki gerilmeleri incelemiştir. Karma bağlantıya sırasıyla 40, 50, 60 ve $70{ }^{\circ} \mathrm{C}$ sıcaklıklar uygulanmış ve sonlu elemanlar yöntemi ile analiz edilmiştir. Çalışma sonucunda sıcaklık artışına bağlı olarak gerilme ve şekil değiştirmelerin önemli oranda arttığ tespit edilmiştir. Aldaş ve Şen [7] yaptıkları çalışmada karma bağlantı uygulanmış farklı metal plakalardaki gerilmeleri incelemişlerdir. Pim bağlantısı ve yapıştırma bağlantısından oluşan karma bağlantı, alt plaka olarak alüminyum sabit tutulurken, üst plaka olarak çelik, bakır, titanyum ve alüminyum kullanılarak modellenmiştir. Karma bağlantıya çekme yükü ve sicaklık yükü birlikte uygulanmış ve alüminyum-alüminyum bağlantılarda diğer bağlantılara oranla daha düşük gerilme değerleri elde edilmiştir. Aldaş ve arkadaşları [8] yapıştırılmış ve pim bağlantısı 
uygulanmış tek bindirme bağlantısında sıcaklık etkisiyle oluşan ısıl gerilmeleri incelemişlerdir. Çözümde ANSYS sonlu elemanlar yazılımı kullanılmıştır. Yapılan çalışmalar sonucunda, gerilmelerin delik çevrelerinde yoğunlaştığı gözlenmiştir.

$\mathrm{Bu}$ çalışmada, seri çift pim bağlantısı ve yapıştırma bağlantısı ile birlikte 6 malzeme kombinasyonları kullanılmak suretiyle karma bağlantılar elde edilmiştir. Bu karma bağlantılara çekme yükü ve farklı sıcaklık yükleri birlikte uygulanmıştır.

\section{MALZEME VE YÖNTEM}

\subsection{Problemin Tanımı}

Bu çalışmada, Şekil 1'de görüldüğü gibi iki adet plakanın öncelikle epoksi türü bir yapıştırıcı ile yapıştırıldığı ve yapıştırılan bu plakalara seri çift pim bağlantısı uygulandığ 1 varsayılmıştır. Çift pim kullanılarak daha rijit bir bağlantı hedeflenmiş ayrıca tek pimde oluşabilecek delik eksenindeki dönme hareketi engellenmiştir. Bağlantısı yapılan plakalar için Tablo 1'de gösterildiği gibi farklı 6 malzeme gurubu kullanılmıştır. Bağlantısı yapılan alt ve üst metal plakaların kalınlığı $2 \mathrm{~mm}$, plaka uzunlukları $125 \mathrm{~mm}$, plaka genişlikleri $25 \mathrm{~mm}$ ve epoksi yapıştırıcı kalınlığı $0.5 \mathrm{~mm}$ olarak modellenmiştir. Pim deliklerinin çapları ise $5 \mathrm{~mm}$ olarak kullanılmıştır.

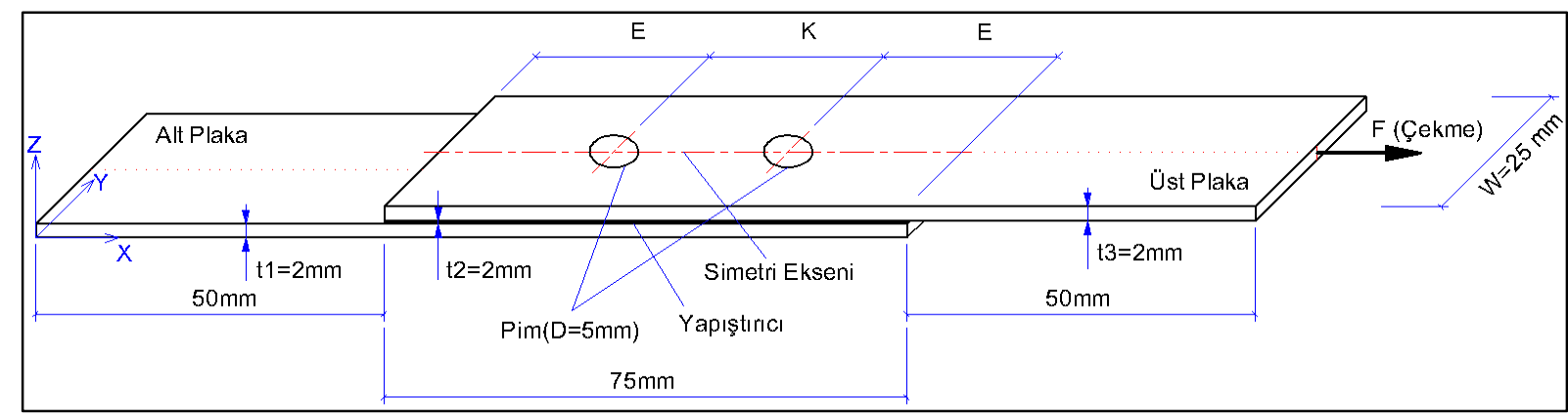

Şekil 1. Karma bağlantı model resmi

\subsection{Malzeme ve Özellikleri}

Bağlantısı yapılan plakalar için farklı malzemeler kullanılarak altı farklı model oluşturulmuştur. Oluşturulan bu karma bağlantılara çekme yükü ve çekme yüküyle birlikte sıcaklık yükü uygulanması sonucunda oluşan gerilme dağılımları incelenmiştir. Tablo 1'de hangi modelde hangi malzemelerin kullanıldığ 1 gösterilmiştir. Metal plakaların mekanik özellikleri ise Tablo 2 ve Tablo 3'te gösterilmiştir [7-9]. 
Tablo 1. Kullanılacak malzeme kombinasyonları

\begin{tabular}{lllll}
\hline & Alt Plaka & Yapıştırıcı & Üst Plaka & Pim \\
\hline Model 1 & Alüminyum & Epoksi & Alüminyum & Çelik \\
Model 2 & Çelik & Epoksi & Çelik & Çelik \\
Model 3 & Titanyum & Epoksi & Titanyum & Çelik \\
Model 4 & Alüminyum & Epoksi & Çelik & Çelik \\
Model 5 & Çelik & Epoksi & Titanyum & Çelik \\
Model 6 & Titanyum & Epoksi & Alüminyum & Çelik \\
\hline
\end{tabular}

Tablo 2. Metal plakaların malzeme özellikleri [9].

\begin{tabular}{lccc}
\hline Özellik & Alüminyum & Çelik & Titanyum \\
\hline Yoğunluk. $\rho\left(\mathrm{kg} / \mathrm{m}^{3}\right)$ & 2710 & 7850 & 4480 \\
Elastiklik Modülü. E $(\mathrm{GPa})$ & 69 & 207 & 110 \\
Poisson oranı. $v$ & 0.33 & 0.30 & 0.34 \\
Isıl Genleşme Katsayısı $\alpha\left(\mu \mathrm{m} / \mathrm{m}^{\circ} \mathrm{C}\right)$ & 23.6 & 11.3 & 9.4 \\
Akma Mukavemeti $(\mathrm{MPa})$ & 117 & 375 & 760 \\
Kopma Mukavemeti $(\mathrm{MPa})$ & 124 & 590 & 790 \\
\hline
\end{tabular}

Tablo 3. Yapıştırıcı malzeme özellikleri [7].

\begin{tabular}{lr}
\hline Özellik & Epoksi \\
\hline Yoğunluk, $\rho\left(\mathrm{kg} / \mathrm{m}^{3}\right)$ & 1264 \\
Elastiklik Modülü, E $(\mathrm{GPa})$ & 3.3 \\
Poisson oranı, $v$ & 0.30 \\
Isıl Genleşme Katsayısı $\alpha\left(\mu \mathrm{m} / \mathrm{m}^{\circ} \mathrm{C}\right)$ & 43.3 \\
Ergime Noktası $T(K)$ & 453 \\
Kaynama Noktası $T(K)$ & 600 \\
\hline
\end{tabular}

\subsection{Sonlu Elemanlar Modelinin Oluşturulması}

Çalışmada ANSYS 12.0 sonlu elemanlar yazılımı kullanılmıştır. Öncelikle problemin katı modeli oluşturulmuş olup model resmi Şekil 2'de görülmektedir. Modellenecek problemin y eksenine simetrik olması sebebiyle yarım modelleme yapılmış olup simetri sınır şartı uy=0 olarak uygulanmıştır. Buradaki amaç, modelleme sonrasında model üzerinde oluşacak eleman ve düğüm sayılarının azaltılması böylece çözüm süresinin kısaltılması ve daha küçük boyutlu sonuç dosyaları elde edilmesidir.

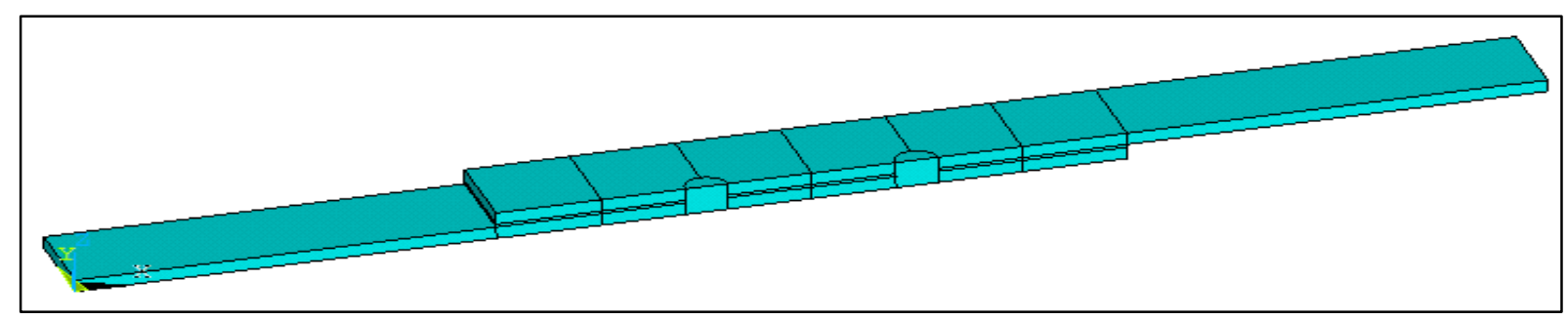

Şekil 2. Karma bağlantı yarım model resmi 
Modelleme işleminin ardından sonlu elemanlar ağ yapısı oluşturulmasına esas teşkil eden eleman tipi seçimi yapılmıştır. Eleman tipi seçimi yapılırken Model 1 için örnek bir analiz yapılarak modellemede en uygun sonucu verecek eleman tipini bulmak amaciyla solid elemanlar arasında kıyaslama yapılmıştır ve kıyaslama tablosu Tablo 4'te gösterilmektedir. En uygun eleman olan Solid 95 seçilmiştir. Şekil 3'te görüldüğü gibi Solid 95" elemanı 20 düğüm noktasına sahip olmasının yanı sıra her bir düğüm noktasında $\mathrm{x}, \mathrm{y}, \mathrm{z}$ yönlerinde yer değiştirme serbestlik derecelerine sahiptir. Yüksek dereceli bir eleman olmasından dolayı düzgün olmayan şekillerde az hata payı ile hesap yapılmasına imkan sağlamaktadır. Ayrıca düzgün dörtyüzlü, prizma ve piramit gibi seçeneklerinin de olması eğri yüzeylerde hassasiyeti artırmaktadır [10].

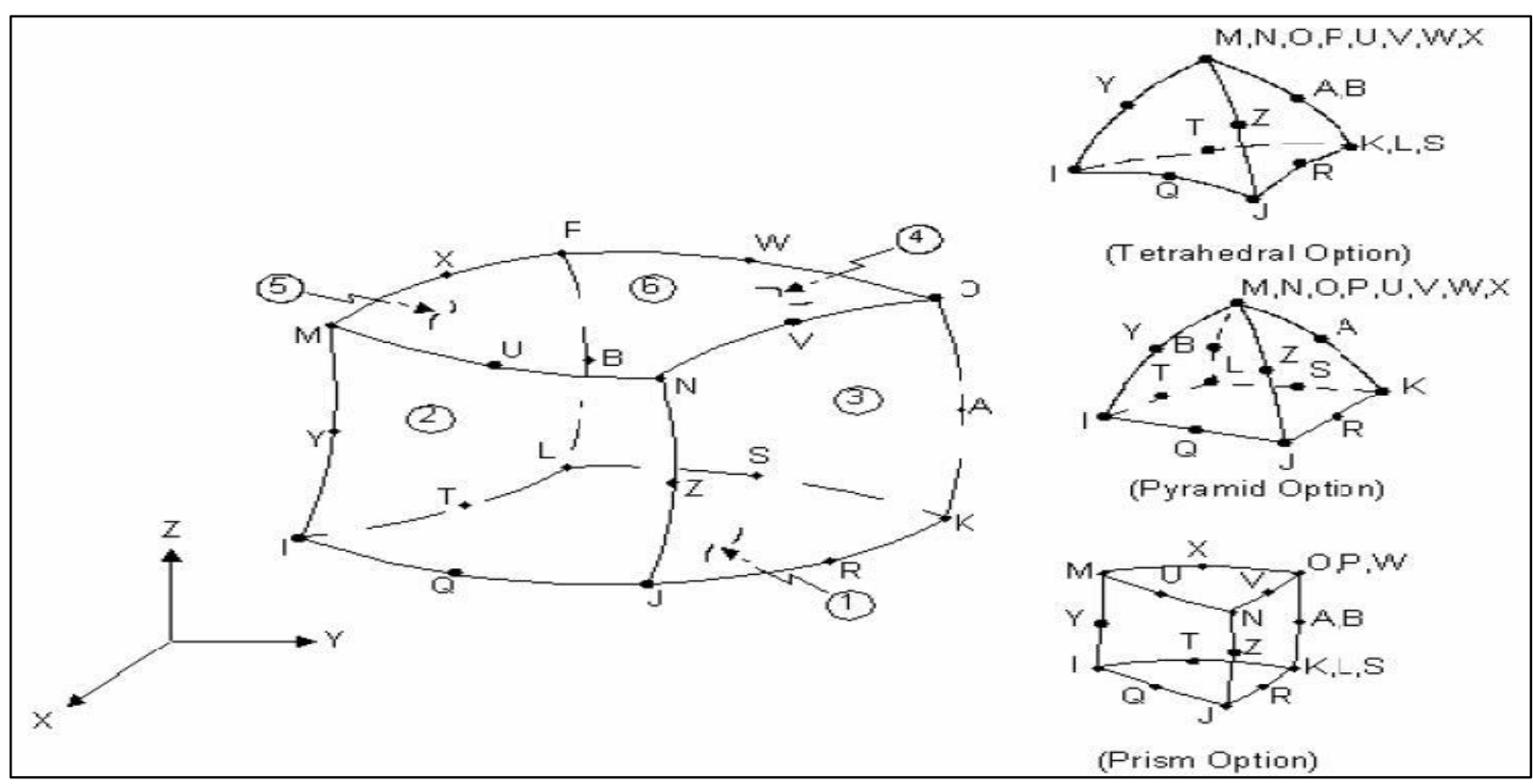

Şekil 3. ANSYS Solid 95 eleman tipi [10].

Tablo 4. Eleman tipi seçimi için kıyaslama değerleri

\begin{tabular}{lccc}
\hline & Eleman Sayısı & Düğüm Noktası & Gerilme Değeri(MPa) \\
\hline Solid 185 & 28800 & 33728 & 621.493 \\
Solid 45 & 28800 & 33728 & 672.472 \\
Solid 95 & 19370 & 88658 & 675.086 \\
\hline
\end{tabular}

Pim ve delik yüzeyleri üzerinde gerçek problemlerde olduğu gibi sonuç alabilmek için kontak yüzey oluşturulmuştur. Kontak eşler iki eleman tipinden oluşmaktadır. Birincisi "TARGET" elemanı pim yanal yüzeylerinde, diğeri ise "CONTACT" elemanı pim deliğinin yüzeylerinde kullanılır. Kontak yüzey oluşturulması aşamasında eleman tipi olarak pim yanal yüzeylerinde TARGE 170, delik yanal yüzeylerinde ise CONTA 174 eleman tipi kullanılmıştır.

Sonlu elemanlar ağ yapısı oluşturulurken, yapıştırıcı ve delik bölgeleri dahil olmak üzere karma bağlantı modelinin tamamında düzgün dörtgen elemanlardan oluşan bir ağ yapısı oluşturulmasına dikkat edilmiştir. Bu düzgün elemanların oluşturulabilmesi için öncelikle 
plakalar ayrı ayrı dörtgen elemanlara bölünmüştür. Bu bölümlerin kendi içinde ağ yapısı oluşturulması suretiyle düzgün bir yapı meydana getirilmiştir. Oluşturulan bu ağ yapıs1 sayesinde çözümlemelerde doğru ve hassas sonuçlar elde edilebilmektedir. Delik çevrelerinde düzgün ağ yapısı oluşturulması oldukça güçtür. Çalışmamızda delik çevreleri de dahil olmak üzere bütün modelde düzgün ağ yapısı oluşturulmuştur. A $\breve{g}$ yapısı oluşturulması işlemi sonucunda model üzerinde 19080 eleman ve 81792 düğüm noktası meydana gelmiştir. Oluşturulan ağ yapısı ve detay resimleri Şekil 4 ile Şekil 5 'te gösterilmektedir

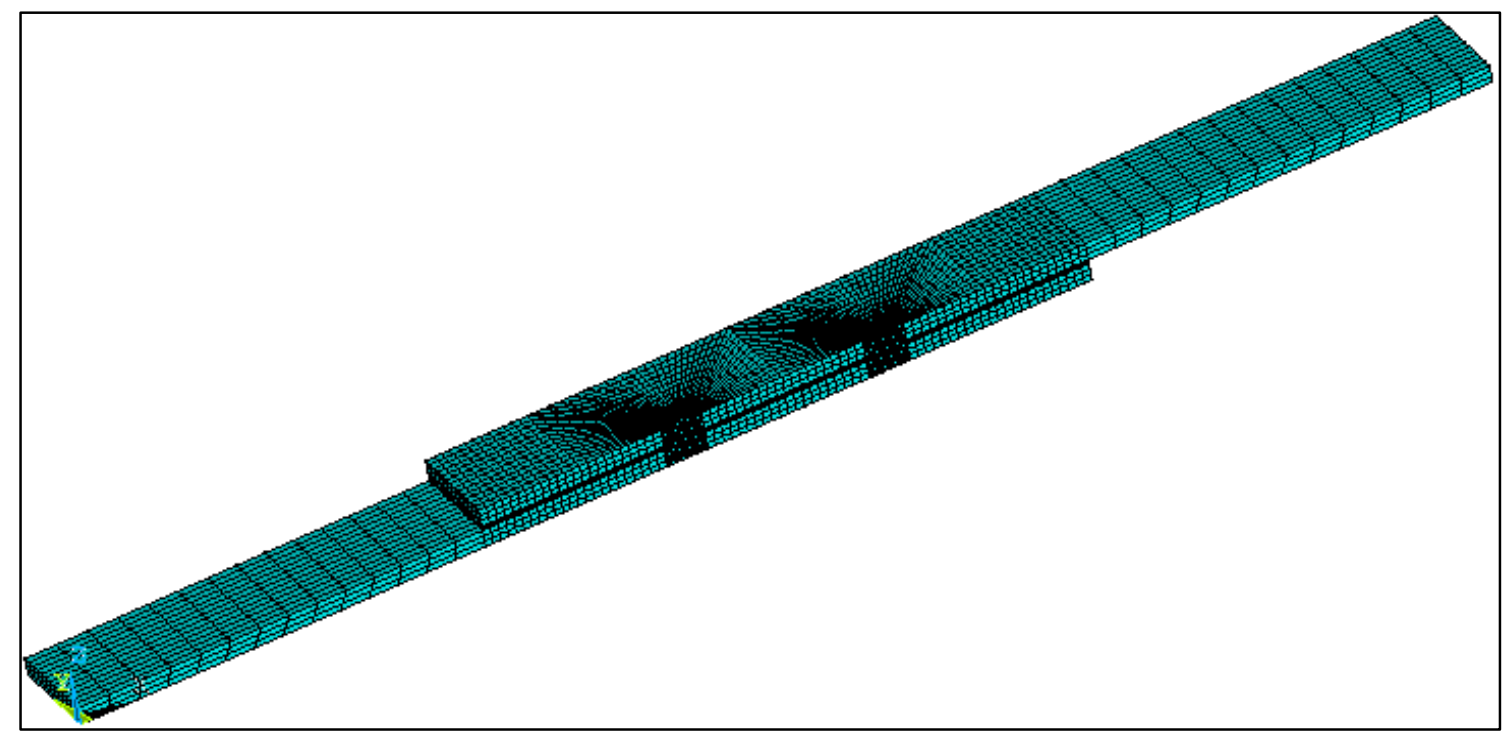

Şekil 4. Modelin tamamının sonlu elemanlar ă̆ yapısı

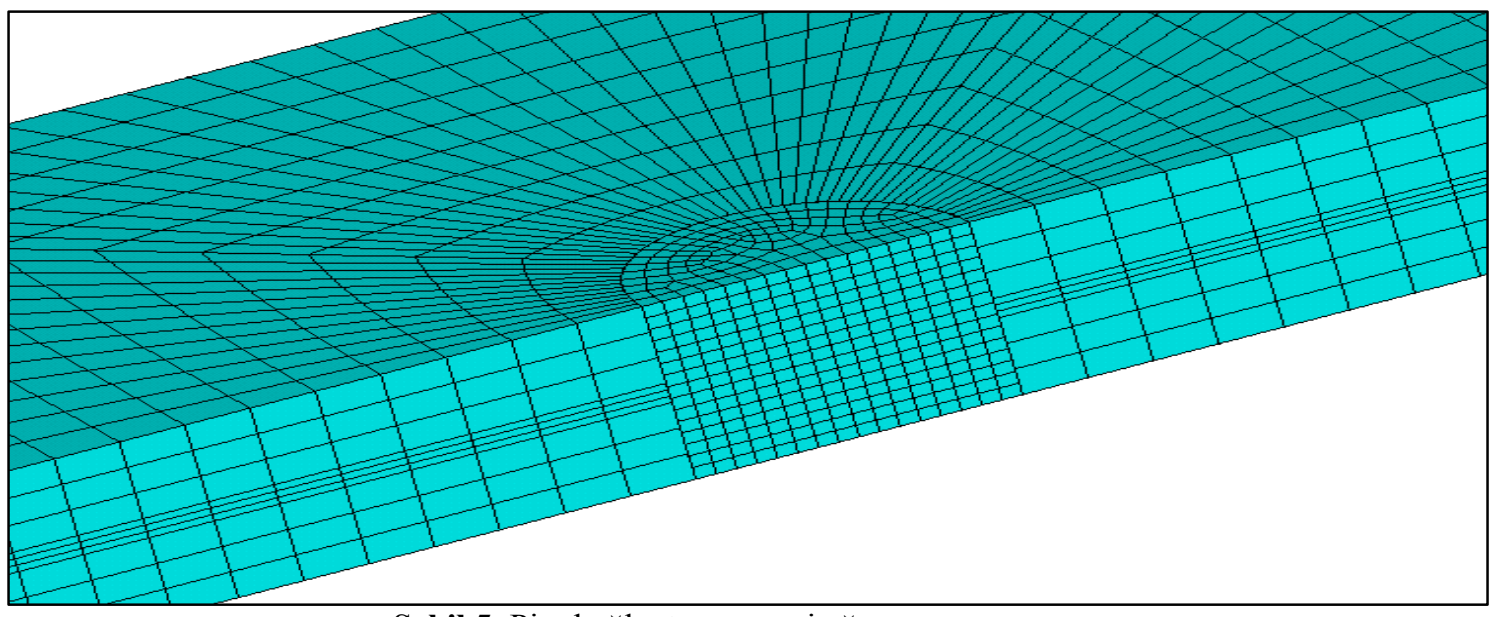

Şekil 5. Pim bağlantısı çevresi ağ yapısı görünümü

Model üzerinde sonlu elemanlar ağ yapısının oluşturulmasının ardından modele bazı sınır şartları uygulanmıştır. Öncelikle model alt plakanın serbest ucundan tutularak ankastre hale getirilmiştir. Daha sonra modelin y ekseni boyunca olan yüzeyleri tutularak uy=0 olacak şekilde y ekseni yönündeki hareket engellenmiş ve pimlerin $\mathrm{z}$ ekseni yönündeki hareketleri sınırlandırılmıştır. Son olarak modele üst plakanın serbest ucundan $50 \mathrm{MPa}$ değerinde negatif 
basınç yükü ile birlikte $50^{\circ} \mathrm{C}$ ve $(-50)^{\circ} \mathrm{C}$ olmak üzere iki farklı 1 sıl yük etki ettirilerek hem negatif basınç hem de farklı ısıl yükler altında oluşan gerilmeler incelenmiştir. Böylece modele hem çekme hem de sıcaklık yükü birlikte etki ettirilmiştir.

\section{BULGULAR VE TARTIŞMA}

\section{1. Çekme Yükü ve $5^{\circ} \mathrm{C}$ Isıl Yük Uygulanması Sonucu Karma Bağlantının Tamamı İçin Elde Edilen Bulgular}

Aşağıda çekme yükü ve $50^{\circ} \mathrm{C}$ 1sıl yük uygulanması sonucunda karma bağlantının tamamı için her bir modelde hesaplanan gerilmelerin maksimum değerleri Tablo 5'te verilmiştir.

Tablo 5. Çekme yükü ve $50^{\circ} \mathrm{C}$ ssıl yük için hesaplanan gerilmelerin (MPa) maksimum değerleri

\begin{tabular}{llrrrc}
\hline & $\mathbf{5 0}^{\circ} \mathbf{C}$ & \multicolumn{1}{c}{$\boldsymbol{\sigma}_{\mathbf{x}}$} & \multicolumn{1}{c}{$\boldsymbol{\sigma}_{\mathbf{y}}$} & \multicolumn{1}{c}{$\boldsymbol{\sigma}_{\mathbf{z}}$} & Von Mises \\
\hline Model 1 & Çekme & 324.39 & 129.62 & 68.95 & 884.14 \\
& Basma & -1108.00 & -810.87 & -880.28 & \\
Model 2 & Çekme & 199.74 & 113.84 & 33.10 & 474.10 \\
& Basma & -573.67 & -444.93 & -573.54 & \\
Model 3 & Çekme & 197.01 & 105.95 & 39.45 & 627.59 \\
& Basma & -726.24 & -582.71 & -745.24 & \\
Model 4 & Çekme & 304.55 & 161.25 & 136.96 & \multirow{2}{*}{919.56} \\
& Basma & -1306.00 & -977.73 & -1152.00 & \\
Model 5 & Çekme & 190.61 & 104.78 & 36.17 & 755.36 \\
& Basma & -605.00 & -472.49 & -583.01 & \\
Model 6 & Çekme & 239.38 & 148.41 & 56.49 & 712.56 \\
& Basma & -1113.00 & -865.01 & -971.84 & \\
\hline
\end{tabular}

Tablo 5'te bütün modellerde maksimum basma normal gerilmelerinin, maksimum çekme normal gerilmelerinden mutlak değer olarak daha yüksek olduğu görülmektedir. Bunun yanında x ekseni yönünde oluşan normal gerilmelerin $\left(\sigma_{\mathrm{x}}\right)$ y ve z eksenlerinde oluşan normal gerilmelere $\left(\sigma_{y^{-}} \sigma_{z}\right)$ nazaran daha yüksek değerlerde olduğu görülmektedir. Bunun sebebi ise bağlantıya uygulanan çekme yükünün x ekseni yönünde olmasıdır.

Modeller karşılaştırıldığında, x ekseni yönünde en yüksek çekme normal gerilmesinin Model 1'de, x ekseni yönünde en yüksek basma normal gerilmesinin Model 4'te; y ve z ekseni yönünde en yüksek çekme ve en yüksek basma normal gerilmelerinin Model 4'te olduğu görülmektedir. Von Mises gerilmelerinde ise en yüksek gerilme değerinin Model 4'te olduğu görülmektedir.

Çekme yükü ve $50^{\circ} \mathrm{C}$ 1sıl yük uygulanması sonucunda karma bağlantının tamamı için elde edilen maksimum normal gerilmelerin grafiksel gösterimi Şekil 6'da, Von Mises gerilmelerinin grafiksel gösterimi ise Şekil 7'de görülmektedir. 


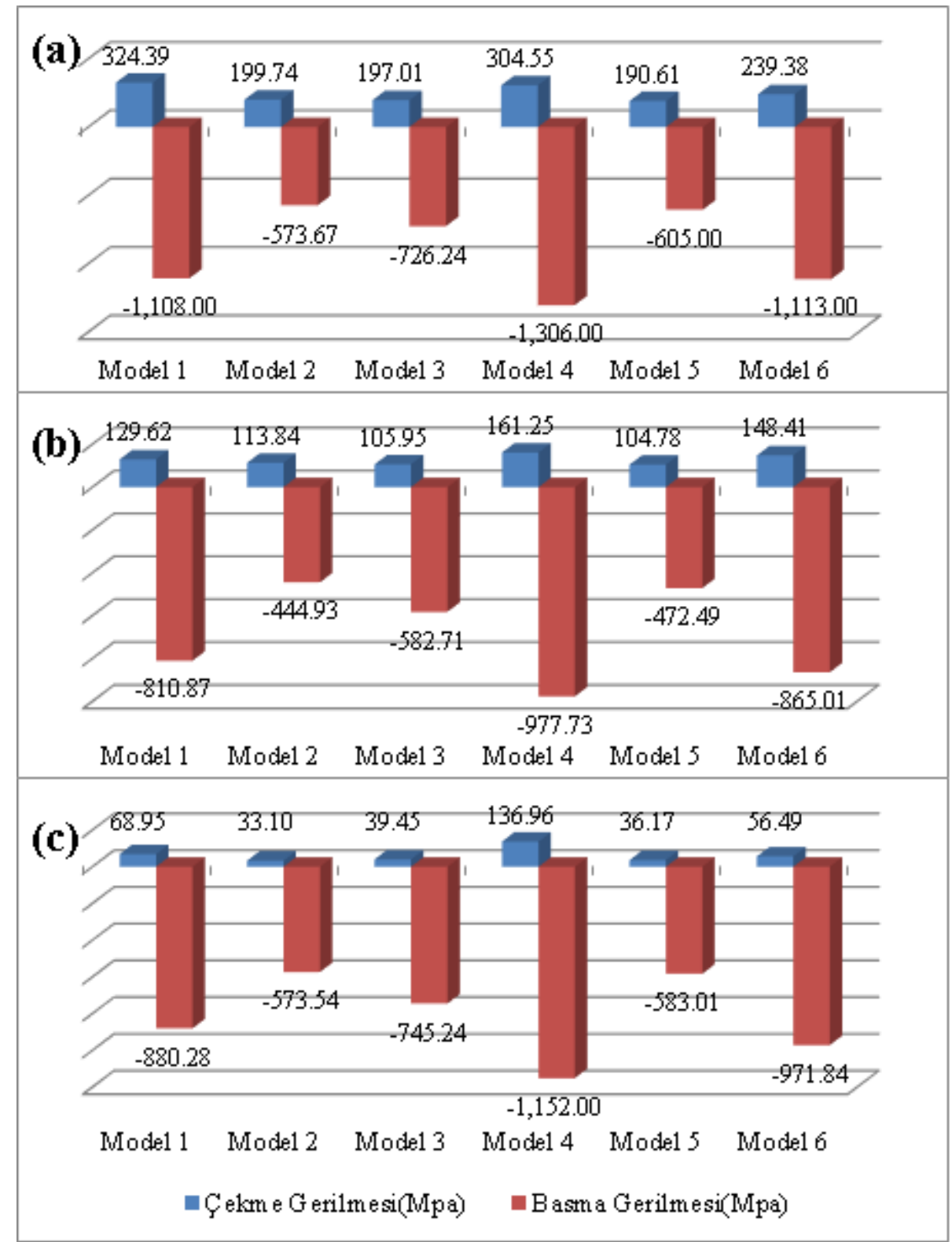

Şekil 6. (a) x ekseni $\left(\sigma_{\mathrm{x}}\right)$, (b) y ekseni $\left(\sigma_{\mathrm{y}}\right)$ ve (c) z ekseni $\left(\sigma_{\mathrm{z}}\right)$ boyunca, çekme yükü ve $50^{\circ} \mathrm{C}$ isll yük uygulanması sonucu maksimum normal gerilmelerin grafiksel gösterimi

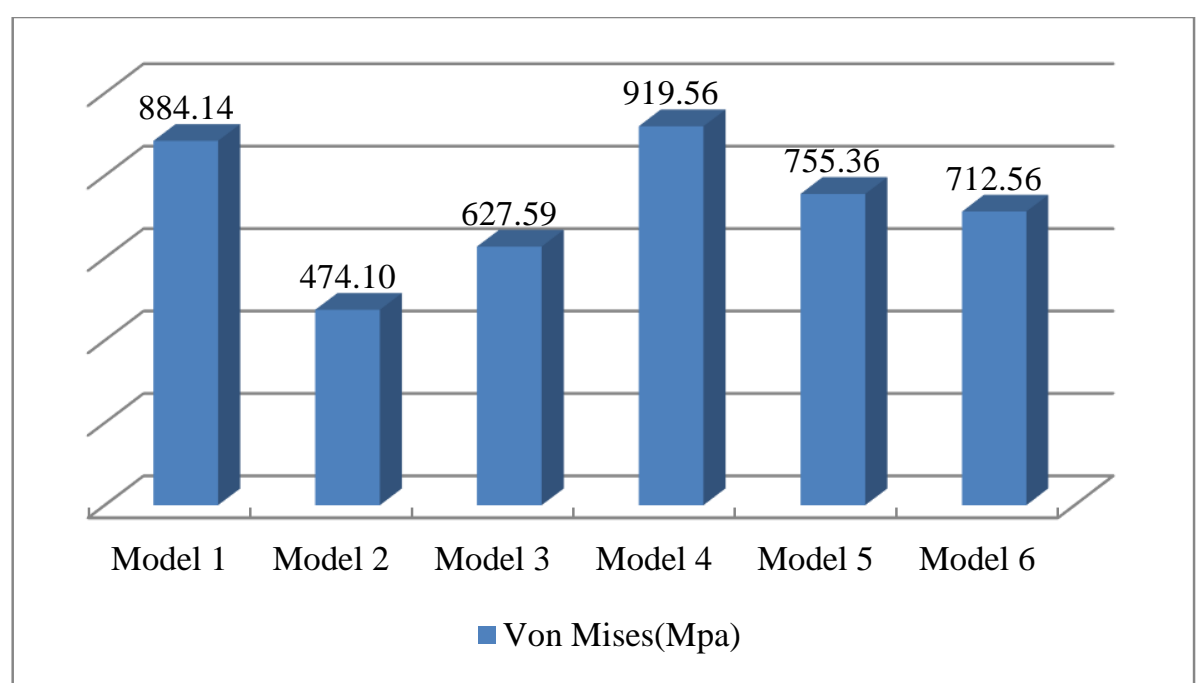

Şekil 7. Çekme yükü ve $50^{\circ} \mathrm{C}$ ssıl yük uygulanması sonucu Von Mises gerilmelerinin grafiksel gösterimi 
Model üzerinde gerilme dağılımlarını, renkli konturları ve gerilme yığılmalarının hangi bölgelerde olduğunu gösteren x ekseni yönündeki normal gerilmelerin model resimleri Şekil 8 'de görülmektedir.
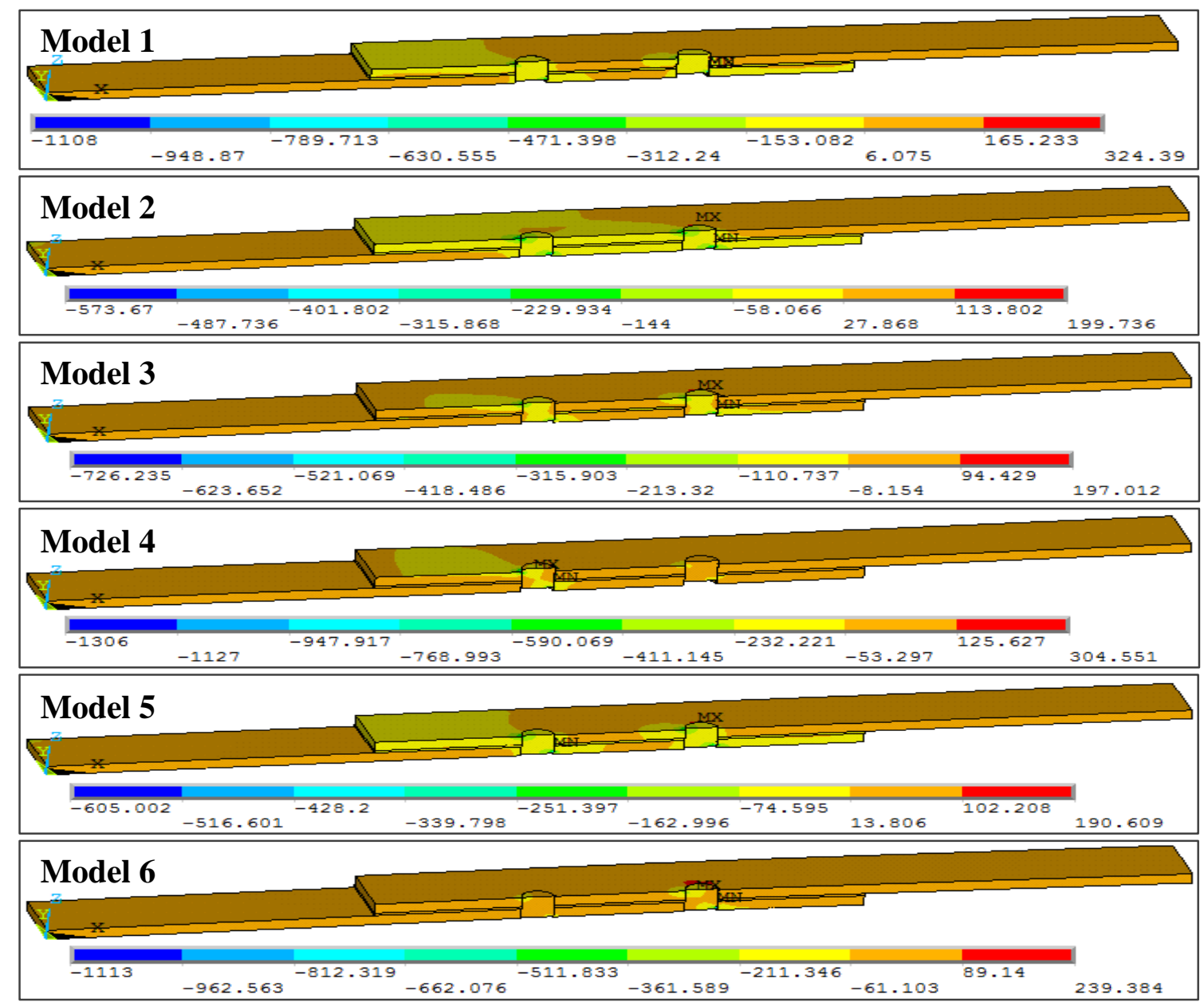

Şekil 8. Çekme yükü ve $50^{\circ} \mathrm{C}$ ssıl yük uygulanması sonucu x yönündeki normal gerilme dağılımları $\left(\sigma_{\mathrm{x}}-\mathrm{MPa}\right)$

\section{2. Çekme Yükü ve $(-50)^{\circ} \mathrm{C}$ Isıl Yük Uygulanması Sonucu Karma Bağlantının Tamamı İçin EIde Edilen Bulgular}

Aşağıda çekme yükü ve $(-50)^{\circ} \mathrm{C}$ 1sıl yük uygulanması sonucunda karma bağlantının tamamı için her bir modelde hesaplanan gerilmelerin maksimum değerleri Tablo 6'da verilmiştir.

Tablo 6' da maksimum basma normal gerilmelerinin, maksimum çekme normal gerilmelerinden mutlak değer olarak daha yüksek meydana geldiği görülmektedir. Ayrıca çekme yükünün x ekseni yönünde olmasından dolayı x ekseni yönünde oluşan normal gerilmeler $\left(\sigma_{\mathrm{x}}\right)$ y ve z eksenlerinde oluşan normal gerilmelere $\left(\sigma_{y^{-}} \sigma_{z}\right)$ oranla yüksek değerlerde oluşmuştur.

Modeller kıyaslanırsa, x, y ve z eksenleri yönünde en yüksek çekme normal gerilmesinin Model 2'de, en yüksek basma normal gerilmesinin ise Model 3'te olduğu görülmektedir. Von Mises gerilmelerinde ise en yüksek gerilme değerinin Model 3’te olduğu görülmektedir. 
Çekme yükü ve $(-50)^{\circ} \mathrm{C}$ ssıl yük uygulanması sonucunda karma bağlantının tamamı için elde edilen maksimum normal gerilmelerin grafiksel gösterimi Şekil 9'da, Von Mises gerilmelerinin grafiksel gösterimi ise Şekil 10’ da görülmektedir.

Tablo 6. Çekme yükü ve $(-50)^{\circ} \mathrm{C}$ ssıl yük için hesaplanan gerilmelerin (MPa) maksimum değerleri

\begin{tabular}{|c|c|c|c|c|c|}
\hline & $(-50){ }^{\circ} \mathrm{C}$ & $\sigma x$ & $\sigma y$ & $\sigma \mathbf{Z}$ & Von Mises \\
\hline \multirow[t]{2}{*}{ Model 1} & Çekme & 312.47 & 229.51 & 221.46 & 1066.00 \\
\hline & Basma & -1017.00 & -800.22 & -686.08 & \\
\hline \multirow[t]{2}{*}{ Model 2} & Çekme & 387.67 & 274.35 & 264.06 & 670.48 \\
\hline & Basma & -646.91 & -496.50 & -368.82 & \\
\hline \multirow[t]{2}{*}{ Model 3} & Çekme & 241.33 & 169.67 & 212.95 & 1405.00 \\
\hline & Basma & -1234.00 & -913.44 & -798.11 & \\
\hline \multirow[t]{2}{*}{ Model 4} & Çekme & 308.34 & 227.81 & 240.04 & 776.38 \\
\hline & Basma & -481.17 & -414.07 & -386.99 & \\
\hline \multirow[t]{2}{*}{ Model 5} & Çekme & 386.59 & 273.96 & 263.68 & 909.62 \\
\hline & Basma & -612.80 & -489.21 & -401.75 & \\
\hline \multirow[t]{2}{*}{ Model 6} & Çekme & 248.28 & 172.68 & 246.96 & 685.40 \\
\hline & Basma & -847.32 & -719.77 & -673.23 & \\
\hline
\end{tabular}

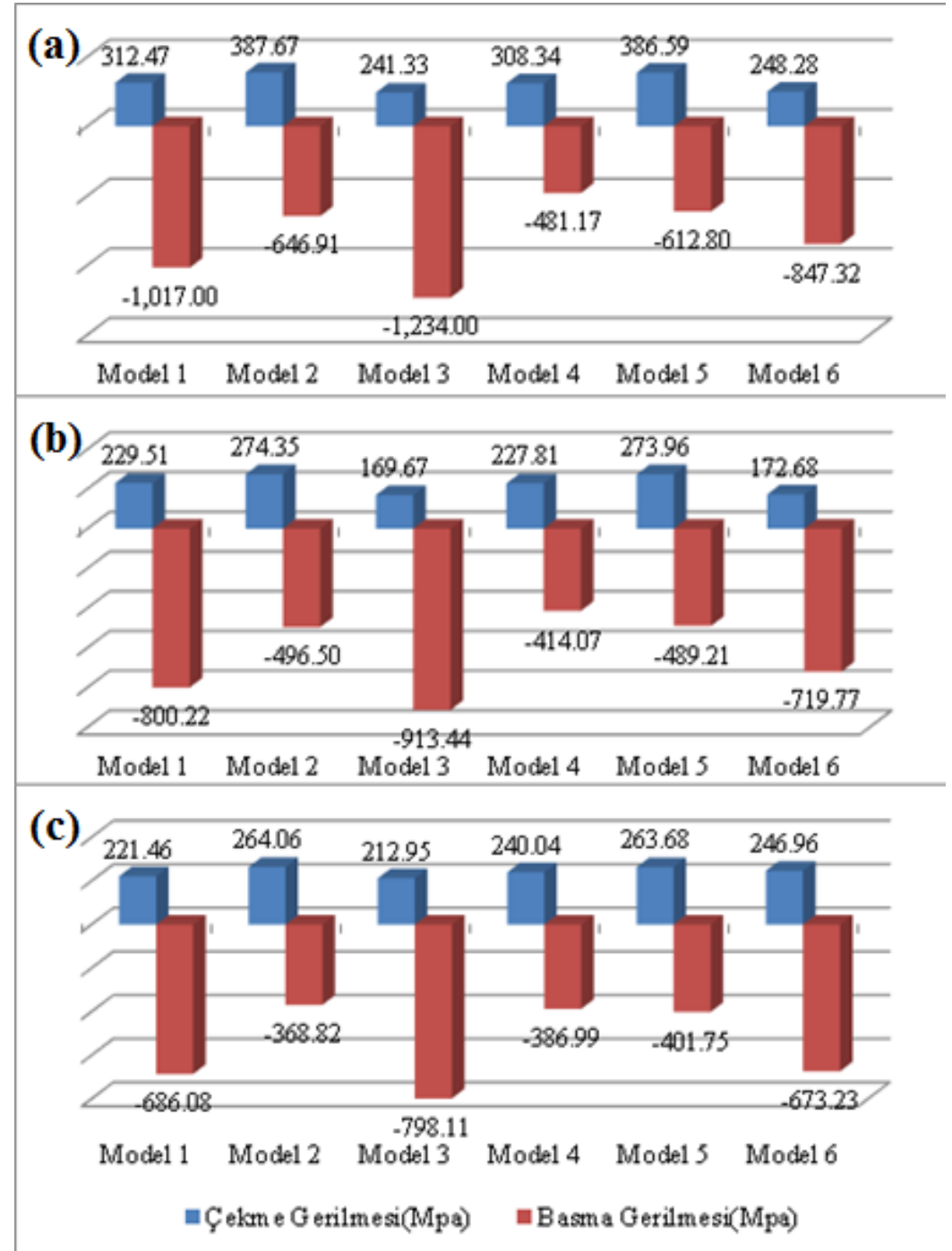

\section{Sekil 9.}

(a) x ekseni $\left(\sigma_{\mathrm{x}}\right)$, (b) y ekseni $\left(\sigma_{\mathrm{y}}\right)$ ve (c) z ekseni $\left(\sigma_{\mathrm{z}}\right)$ boyunca, çekme yükü ve $(-50)^{\circ} \mathrm{C}$ isll yük uygulanması sonucu maksimum normal gerilmelerin grafiksel gösterimi 


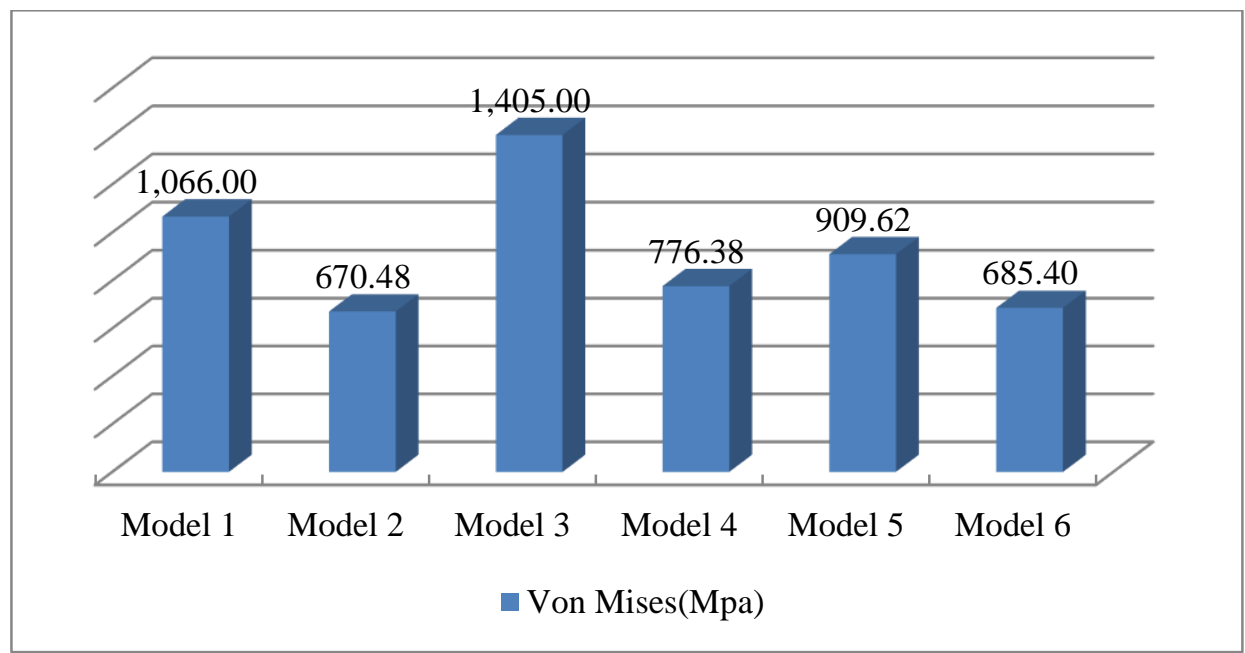

Şekil 10. Çekme yükü ve $(-50)^{\circ} \mathrm{C}$ ssıl yük uygulanması sonucu Von Mises gerilmelerinin grafiksel gösterimi.

Model üzerinde gerilme dağılımlarını, renkli konturları ve gerilme yığılmalarının hangi bölgelerde olduğunu gösteren x ekseni yönündeki normal gerilmelerin model resimleri Şekil 11 'de görülmektedir.

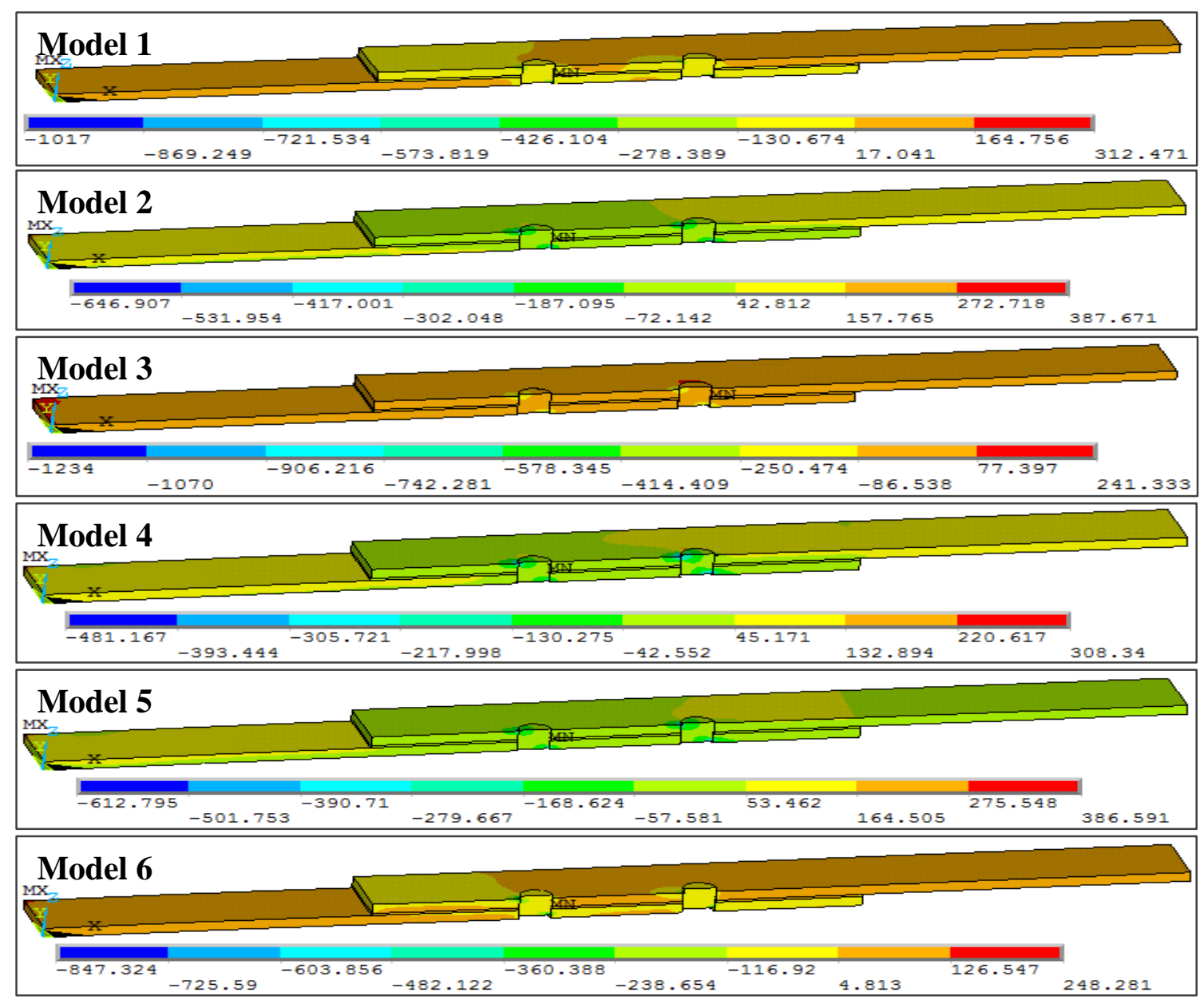

Şekil 11. Çekme yükü ve $-50^{\circ} \mathrm{C}$ ssıl yük uygulanması sonucu x yönündeki normal gerilme dağılımları $\left(\sigma_{\mathrm{x}}-\mathrm{MPa}\right)$ 


\subsection{Modellerin Delik Bölgelerinin Farklı Yükler Altındaki Gerilmelerinin Karşılaştırılması}

Gerilmeler Şekil 12'de gösterilen A-C ve D-F doğrultuları tanımlanarak hesaplanmıştır. Bu doğrultular boyunca dönme açısı A ve D noktalarında $\theta=0^{\circ}$, B ve E noktalarında $\theta=90^{\circ}$, C ve F noktalarında $\theta=180^{\circ}$ olacak şekilde tanımlanmıştır. Şekil 13-14'te görüldüğü gibi A-C boyunca ve D-F boyunca toplam 209 dügüm noktasında meydana gelen gerilmeler esas alınarak grafikler çizilmiştir.

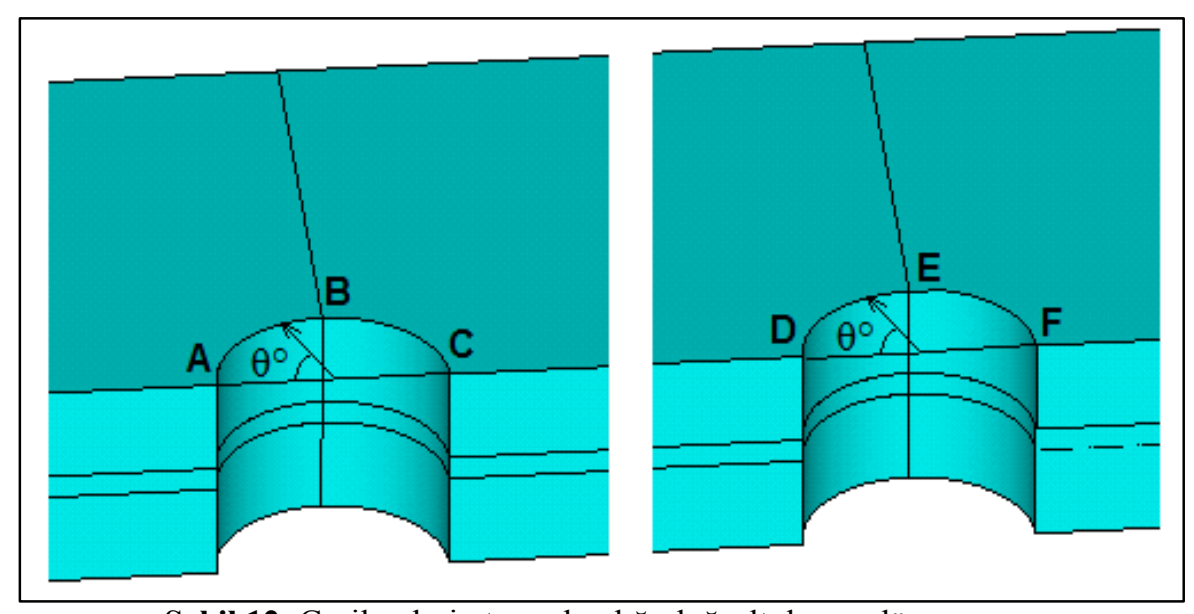

Şekil 12. Gerilmelerin tanımlandığı doğrultular ve dönme açısı

\section{SONUÇLAR}

$\mathrm{Bu}$ çalışmada oluşturulan altı modelle $50 \mathrm{MPa}$ değerinde çekme yükü ile birlikte farklı değerlerde sıcaklık yükü uygulanmış ve yapılan gerilme analizlerinde aşağıdaki sonuçlar elde edilmiştir.

Modellere çekme yükü ile birlikte $50^{\circ} \mathrm{C}$ ssıl yük uygulanması sonucunda x ve y eksenleri yönünde gerilmelerde genel olarak bir artma görülmüş, z ekseni yönünde meydana gelen gerilmelerde ise azalma görülmüştür. Modellere çekme yükü ile birlikte $(-50)^{\circ} \mathrm{C}$ ssıl yük uygulanması sonucunda ise $\mathrm{x}$, y ve $\mathrm{z}$ eksenleri yönünde gerilmelerde yükselme meydana gelmiştir.

Modellerde çekme yükü ile birlikte uygulanan farklı ısıl yükler sonucunda, en yüksek gerilme $\mathrm{x}, \mathrm{y}$ ve $\mathrm{z}$ eksenleri yönünde $(-50)^{\circ} \mathrm{C}$ ssıl yük altında Model 2 'de meydana gelmiştir. En düşük gerilme ise $\mathrm{x}$, y ve z eksenleri yönünde $50^{\circ} \mathrm{C} 1 \mathrm{~s} 1$ l yük altında Model 5 'te meydana gelmiştir.

Delik bölgeleri incelendiğinde, çekme yükü ile birlikte $50^{\circ} \mathrm{C}$ 1sıl yük uygulanması sonucunda, Model 1, Model 4 ve Model 5'te x ekseni yönündeki gerilmelerde bir artış meydana gelirken Model 2, Model 3 ve Model 6'da meydana gelen gerilmelerde azalma oluşmuştur. Çekme yükü ile birlikte $(-50)^{\circ} \mathrm{C}$ 1sıl yük uygulanması sonucunda ise Model 2, Model 3 ve Model 6' da x 
ekseni yönündeki gerilmelerde bir artış meydana gelirken Model 1, Model 4 ve Model 5'te meydana gelen gerilmelerde azalma oluşmuştur.
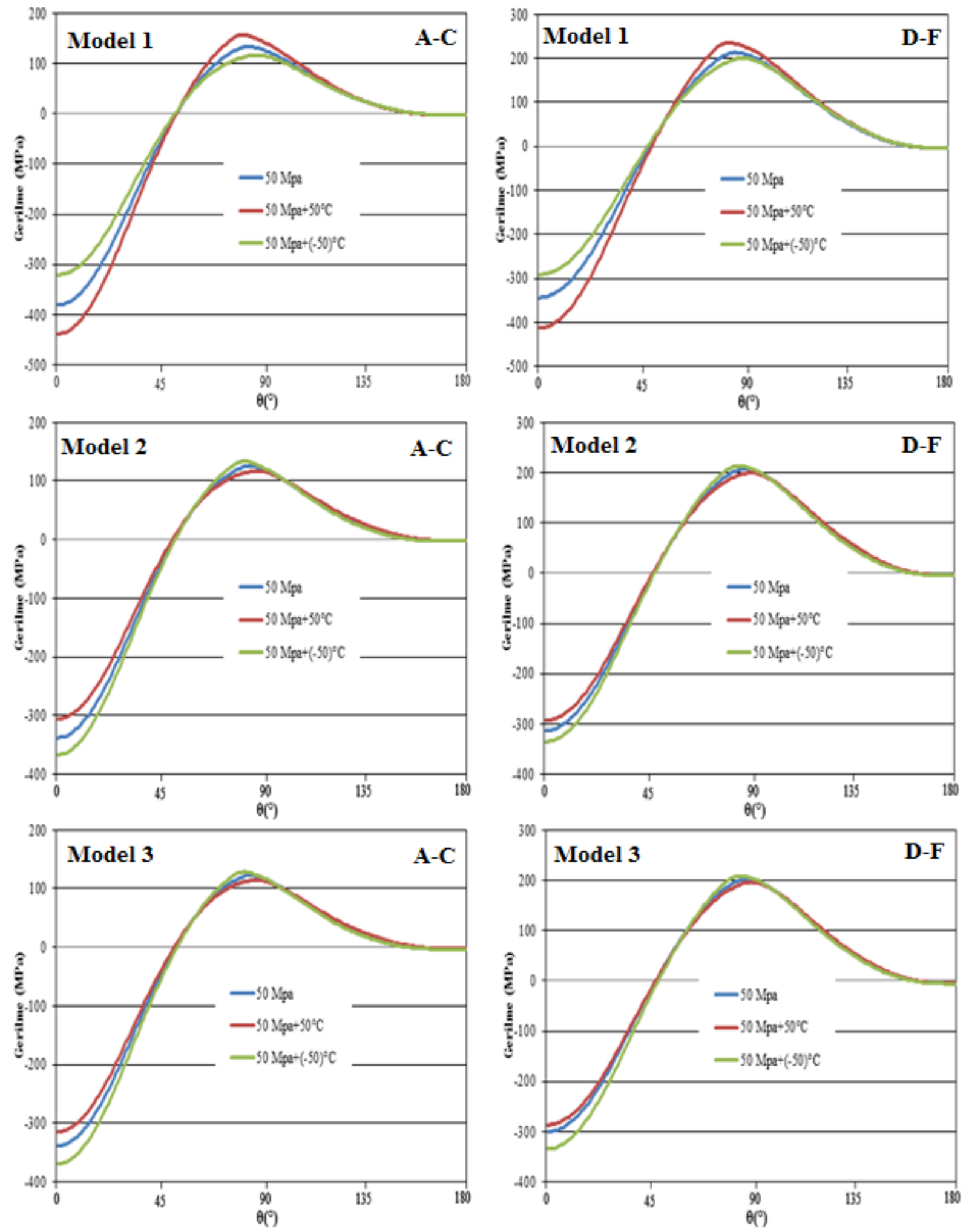

Şekil 13. Model 1, Model 2 ve Model 3 için A-C ve D-F boyunca meydana gelen x yönündeki normal gerilmeler $\left(\sigma_{\mathrm{x}}-\mathrm{MPa}\right)$ 

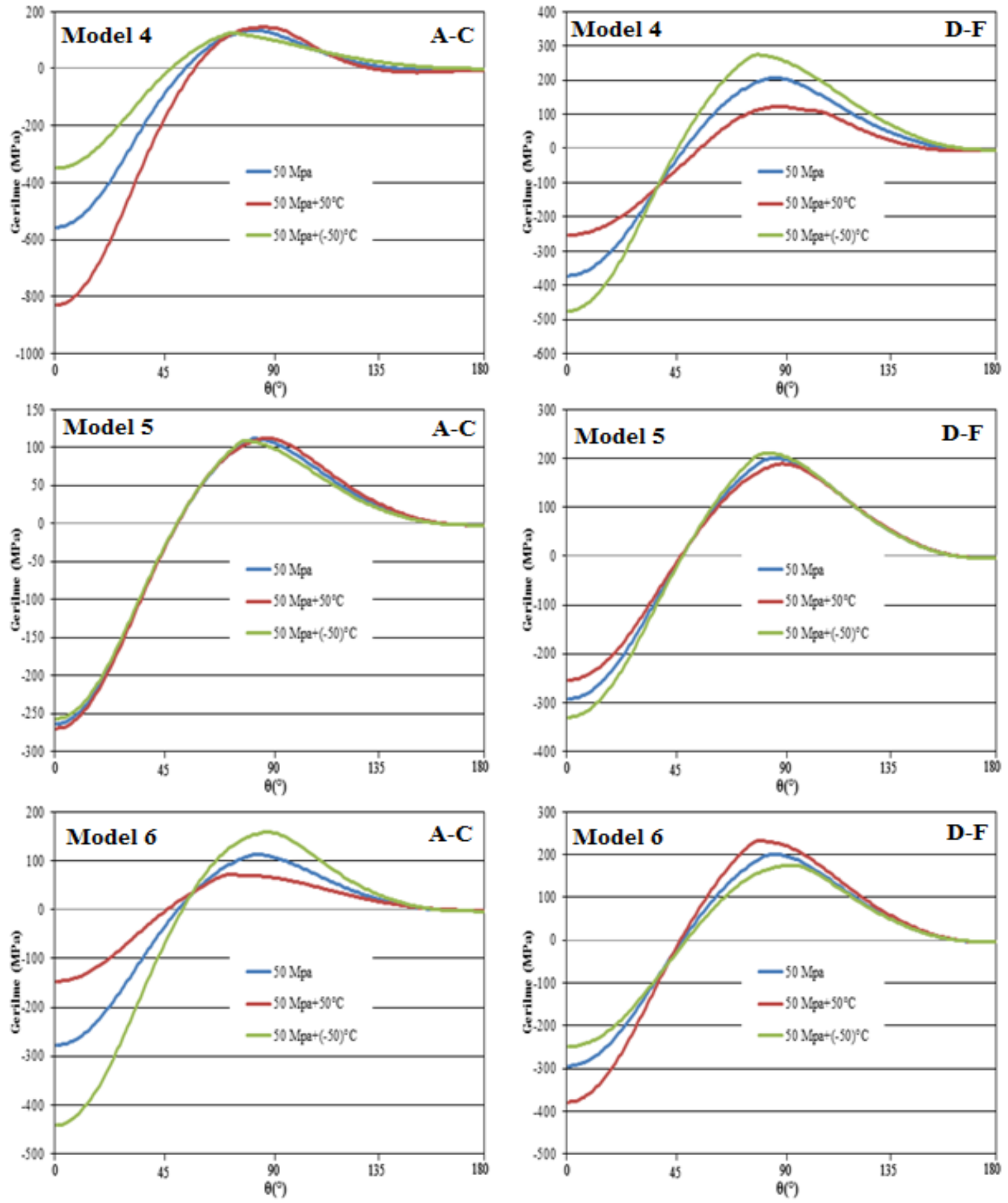

Şekil 14. Model 4, Model 5 ve Model 6 için A-C ve D-F boyunca meydana gelen x yönündeki normal gerilmeler $\left(\sigma_{\mathrm{x}}-\mathrm{MPa}\right)$

\section{KAYNAKLAR}

[1] K. Aldaş, F. Şen, Karma bağlantı uygulanmış farklı metal plakalarda meydana gelen gerilmelerin incelenmesi. Makine Teknolojileri Elektronik Dergisi, 8(2) (2011) 1-12.

[2] M. Jackerle, Finite element analysis and simulation of adhesive bonding, soldering and brazing: A bibliography. Modeling and Simulation in Materials Science and Engineering, 5 (1976-1996) 159-185. 
[3] W.S. Chan and S. Vedhagiri, Analysis of composites bolted-bonded joints used in repairing. Journal of Composite Materials, 35(12) (2001) 1045-1061.

[4] M.K. Apalak, K. Aldaş and F. Şen, Thermal non-linear stresses in an adhesively bonded and laser-spot welded single-lap joint during laser-metal interaction. Journal of Materials Processing Technology, 142 (2003) 1-19.

[5] F. Şen, M. Pakdil, O. Sayman and S. Benli, Experimental failure analysis of mechanically fastened joints with clearance in composite laminates under preload. Materials \& Design, 29 (2003) 1159-1169.

[6] F. Şen and K. Aldaş, Sıcaklık değişiminin yapıştırmalı ve pimli alüminyum plakalardaki gerilmeler üzerine etkisi. TUBAV Bilim Dergisi, 3(4) (2010) 323-329.

[7] K. Aldaş and F. Şen, Karma bağlantı uygulanmış farklı metal plakalarda meydana gelen gerilmelerin incelenmesi. Makine Teknolojileri Elektronik Dergisi, 8(2) (2011) 1-12.

[8] K. Aldaş, F. Şen and H. Palancioğlu, Stress analysis of adhesively bonded ad pinned single lap joints using three dimensional finite element models. Journel of Theoretical and Applied Mechanics, 41(2) (2011) 3-20.

[9] W.D. Callister, Materials science and engineering: an introduction-7th edition (John Wiley and Sons, New York, 2007).

[10] ANSYS, Release 10.0 Documentation, Swanson Analysis System Inc. (Houston, PA, USA 2005). 